\title{
$\mathrm{ErAs}$ 나노입자가 첨가된 $\mathrm{InGaAlAs}$ 박막의 평면정렬방향으로의 열전특성 \\ 이영중 ${ }^{\dagger}$ \\ 경북대학교 기계공학부
}

\section{In-Plane Thermoelectric Properties of InGaAlAs Thin Film with Embedded ErAs Nanoparticles}

\author{
Yong Joong Lee \\ School of Mechanical Engineering, Kyungpook National University, Daegu 702-701, Korea
}

(2011년 7월 6일 접수 : 2011년 7월 30일 최종수정 : 2011년 7월 30일 채택)

\begin{abstract}
Microelectromechanical systems (MEMS)-fabricated suspended devices were used to measure the in-plane electrical conductivity, Seebeck coefficient, and thermal conductivity of $304 \mathrm{~nm}$ and $516 \mathrm{~nm}$ thick InGaAlAs films with $0.3 \%$ ErAs nanoparticle inclusions by volume. The suspended device allows comprehensive thermoelectric property measurements from a single thin film or nanowire sample. Both thin film samples have identical material compositions and the sole difference is in the sample thickness. The measured Seebeck coefficient, electrical conductivity, and thermal conductivity were all larger in magnitude for the thicker sample. While the relative change in values was dependent on the temperature, the thermal conductivity demonstrated the largest decrease for the thinner sample in the measurement temperature range of $325 \mathrm{~K}$ to 425 $\mathrm{K}$. This could be a result of the increased phonon scattering due to the surface defects and included ErAs nanoparticles. Similar to the results from other material systems, the combination of the measured data resulted in higher values of the thermoelectric figure of merit (ZT) for the thinner sample; this result supports the theory that the reduced dimensionality, such as in twodimensional thin films or one-dimensional nanowires, can enhance the thermoelectric figure of merit compared with bulk threedimensional materials. The results strengthen and provide a possible direction in locating and optimizing thermoelectric materials for energy applications.
\end{abstract}

Key words $\underline{Z T}$, InGaAlAs, Seebeck coefficient, thermal conductivity, electrical conductivity.

1. 서

열전물질은 열에너지를 전기에너지로 변환시켜 에너지 재 활용을 가능하게 하는 물질로서 차세대 그린 에너지원의 하나로 그 동안 꾸준히 연구되어 왔다. 그럼에도 불구하 고 열-전기에너지 변환 효율이 높지 않아 군사 및 우주탐 사와 같은 특정 분야에 제한적으로 사용되어 왔다. 하지 만 Hicks and Dresselhaus에 의해서 ${ }^{1)}$ 열-전기에너지 변환 효율이 1차 또는 2차원 나노선 및 박막 물질에서 획기적 으로 증가 할 수 있음이 이론적으로 밝혀진 이후, 많은 연 구자들이 저차원 나노 또는 마이크로 스케일의 열전소자 연구에 집중하기 시작하였다. 이는 다음과 같이 표현되는 열전성능을 나타내는 열전성능지수(thermoelectric figure of merit, ZT)를 통해 보다 자세하게 이해할 수 있다.

$$
Z T=\frac{S^{2} \sigma}{\kappa} T
$$

\footnotetext{
${ }^{\dagger}$ Corresponding author

E-Mail : yjlee76@knu.ac.kr (Y. J. Lee)
}

$Z$ 값은 제베크 계수(Seebeck coefficient, S)의 제곱과 전기전도도(electrical conductivity, $\sigma$ )에 비례하며 열전도 도(thermal conductivity, $\kappa)$ 에는 반비례한다. 즉, $Z$ 값은 전기전도도 대 열전도도의 비율에 비례한다. 하지만 일 반적으로 전기전도도는 열전도도에 비례하기 때문에 $Z$ 값 을 임의로 조절하기는 어렵다. 예를 들어 도체의 경우 열 전도도와 함께 전기전도도 높아 상대적으로 $Z$ 값이 크지 않으며, 부도체의 경우 열전도도와 전기전도도가 함께 낮 아 $Z$ 값을 임의로 증가시킬 수 없다. 특히, 금속의 경우 비드만-프란츠 (Wiedeman-Franz law) 법칙에 따라 열전 도도 대 전기전도도의 비율이 로렌츠 상수로 특정화 되 어있다. 이런 이유로 지금까지의 열전물질 연구는 주로 반금속이나 반도체 물질에 집중되어 왔다. 이는 불순물 도핑을 이용해서 전기전도도와 열전도도를 부분적으로 분 리 조절할 수 있었기 때문이다. 이에 비해서 Hicks and Dresselhaus는 저차원- 1차 또는 2 차원- 물질의 경우 $Z T$ 값이 벌크에서와 상이하게 증가할 수 있다는 획기적인 이 론을 밝혀냈다. 이는 저차원에서는 quantum confinement 
현상으로 인해서 전기전도도와 열전도도의 감소비율이 상 이하기 때문에 $Z$ 값이 크게 증가하는 것으로 알려졌다. 이 후 여러 물질계를 대상으로 진행된 연구 결과들은 박막 또는 나노선의 $Z T$ 값은 동일 물성의 벌크값보다 박막의 두 께 또는 나노선의 지름이 감소함에 따라 증가함을 실험 적으로 증명하였다. ${ }^{2-5)}$ 이는 박막 두께 감소에 따라 부피 대비 표면적이 증가하여 표면 defect에 의한 phonon의 산 란이 벌크에서 보다 용이하게 됨으로써 phonon에 의한 열 전달 감소에 의한 열전도도 감소가 발생하는 반면, 전기 전도도는 표면 전하의 defect 산란에 다소 적게 영향을 받으므로, 상대적으로 $\sigma / \kappa$ 비율이 벌크에서 보다 상당히 증가하기 때문인 것으로 이해되어 왔다.

하지만 2 차원 박막 또는 1 차원 나노선 소자의 경우 시 료의 극소성으로 인해서 열전소자로서의 효율을 나타내는 열전성능지수 $(Z T)$ 를 결정하는 전기전도도, 열전도도 및 제 베크 계수의 동일 시료에서의 일괄 측정이 난이 한 것 으로 알려져 왔다. 이에 따라 MEMS 방법을 활용하여 제 작한 서스펜디드 디바이스를 이용하여 저차원 열전소자의 열전특성을 결정하는 세 가지 변수를 동일 시료에서 모 두 측정하는 방법이 최근 알려졌다. ${ }^{6}$ 이러한 서스펜디드 디바이스를 이용하는 방법은 $3 \omega$ 등의 방식과 달리 동일 시료로부터 열전도도, 전기전도도 및 제베크계수를 측정 할 수 있다는 장점이 있다.

본 논문은 InGaAlAs 박막에 $\mathrm{ErAs}$ 나노입자를 불순물 의 형태로 첨가하여 전하밀도를 증가시킴으로써 전기전 도도를 상승시키고 동시에 phonon의 산란을 유발하여 열 전도도를 저하시킬 수 있는지를 연구하였다. 이를 위하 여 두께가 상이한 두개의 박막시료를 서스펜디드 디바이 스 위에 옮겨 놓고 평면정렬방향에서의 열전도도, 전기 전도도, 제베크 계수를 측정 및 비교하였다.

\section{2. 실험 방법}

$\mathrm{ErAs}$ 나노입자가 첨가된 InGaAlAs 박막은 $\mathrm{MBE}$ (molecular beam epitaxy) 장비를 이용하여 격자가 정합되는 (100) $\mathrm{InP}$ 웨이퍼를 기판으로 합성되었다. ${ }^{7,99} \mathrm{InGaAlAs}$ digital alloy는 $80 \%$ 의 n-type InGaAs와 $20 \%$ 의 n-type InAlAs 초격자를 쌓아 만들어졌다. ErAs 나노입자의 박막 내 밀도는 $0.3 \%$ 로, 이는 대략 $10^{19} \mathrm{~cm}^{-3}$ 의 도핑에 해당한 다. 전자현미경 측정에 의하면 본 연구에서 측정한 박막 시료의 두께는 $304 \pm 13 \mathrm{~nm}$ 와 $516 \pm 50 \mathrm{~nm}$ 이다. 길이 25 $35 \mu \mathrm{m}$, 넓이 $3 \sim 5 \mu \mathrm{m}$ 막대형태의 박막 시료는 PMMA (poly-methyl-methacrylate) resist를 사용하여 전자빔노광 (electron beam lithography)을 통해 제작되었다.

시료를 만들기 위한 공정은 Fig. 1에 나와 있다. 전자 빔노광과 인화과정을 거친 후 전자빔 레지스트에 의해

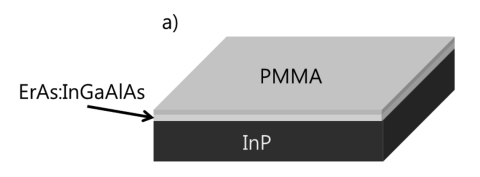

c)

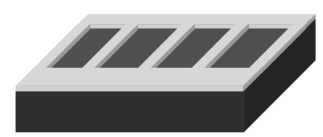

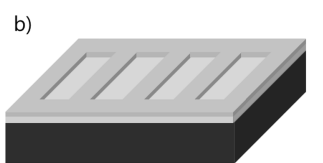

d)

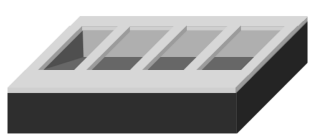

Fig. 1. ErAs : InGaAlAs thin film fabrication steps. a) PMMA coated sample before electron beam lithography (EBL). b) Sample pattern after EBL and development. c) Transfer of EBL pattern to ErAs : InGaAlAs film layer using deionized (DI) $\mathrm{H}_{2} \mathrm{O}: \mathrm{H}_{2} \mathrm{O}_{2}: \mathrm{H}_{3} \mathrm{PO}_{4}$ etchant. d) Suspended ErAs : InGaAlAs film after etching in DI $\mathrm{H}_{2} \mathrm{O}: \mathrm{HCl}$ (See Fig. 2).

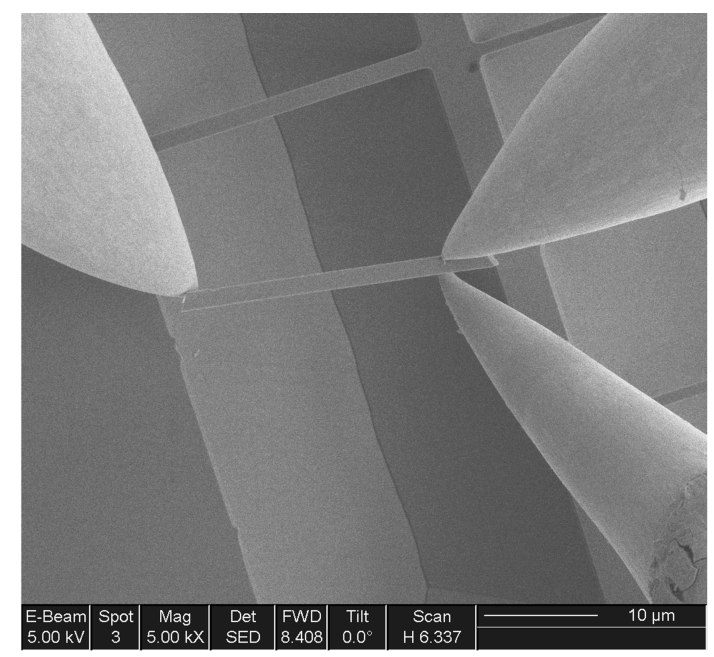

Fig. 2. SEM figure demonstrating how a patterned film can be picked up by the nano-manipulation operation for transferring to a suspended device.

보호되지 않은 InGaAlAs 박막은 탈염수(deionized water, $\left.\mathrm{H}_{2} \mathrm{O}\right)$ : 과산화수소 $\left(\mathrm{H}_{2} \mathrm{O}_{2}\right)$ : 인산 $\left(\mathrm{H}_{3} \mathrm{PO}_{4}\right)$ 의 비율이 $15: 5: 1$ 로 섞인 용액을 (식각률 $~ 100 \mathrm{~nm} / \mathrm{min}$ ) 사용하여 식각하 였다. InGaAlAs 밑에 있는 InP 기판은 탈염수 : 염산의 비율이 $1: 5$ 인 용액을 사용하여 약 20 분간 식각하였다. 전자빔노광이 되지 않아 인화공정 후 여전히 전자빔 레 지스트로 덮여있어 보호된 부분은 에칭이 되지 않지만, $\mathrm{InGaAlAs}$ 식각 후 노출된 $\mathrm{InP}$ 기판은 에칭이 되므로 InGaAlAs 박막을 InP 기판으로부터 서스펜드 시킬 수 있 었다. 이는 탈염수 : 염산 용액은 InGaAlAs 박막을 식각 하지 않고 $\mathrm{InP}$ 기판만을 선택적으로 식각하기 때문이다. 박막 위에 남아있던 전자빔레지스트는 아세톤 세척 공정 을 통해서 제거하였다. 그 후 SEM (주사식 전자현미경) 안에 설치된 nano-maipulator를 사용하여 제작된 박막을 서 스펜디드 디바이스로 이동시켰다. Fig. 2에 보이는 것처럼 2 개 또는 3 개의 바늘 형태로 식각된 텅스텐 팁을 가지고 


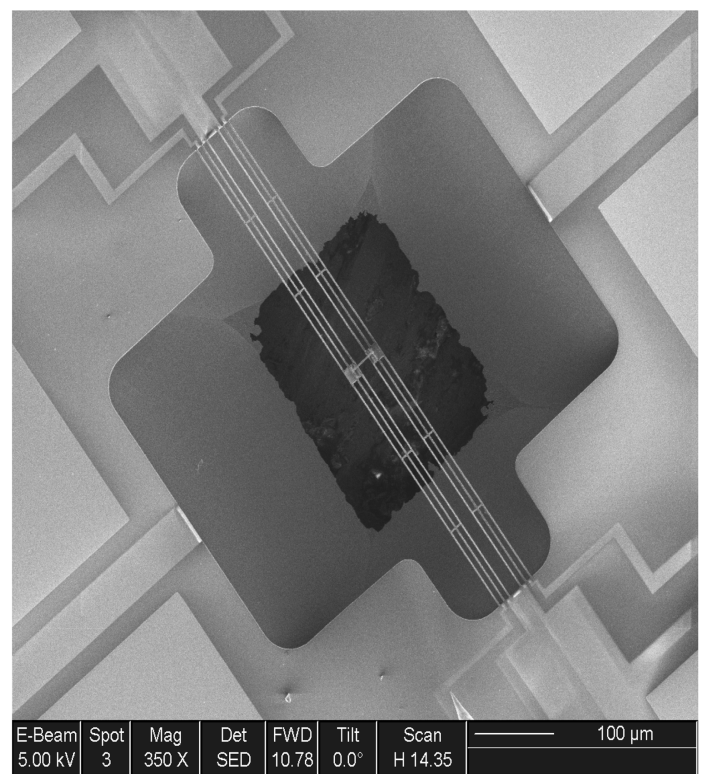

Fig. 3. SEM figure showing a suspended device with a sample film transferred. A set of six beams supporting a membrane is clearly visible.

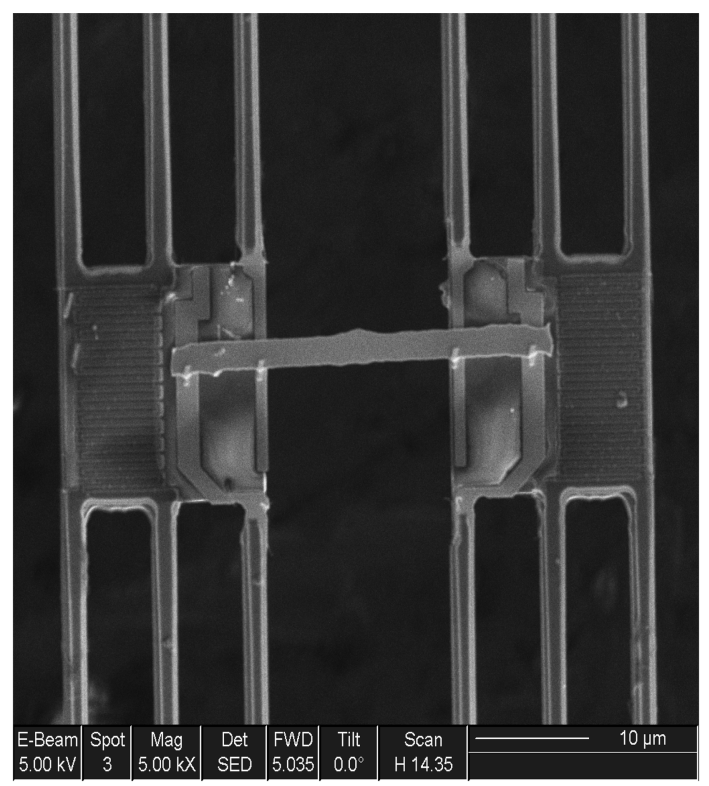

Fig. 4. SEM figure showing a suspended region of the device showing a transferred sample with deposited electrical contacts.

젓가락을 사용하듯 박막을 집어 이동시켰다. Fig. 3는 서 스펜디드 디바이스와 그 위에 옮겨진 박막 시료을 보여 주는 전자현미경 사진이다.

Fig. 3에서 볼 수 있듯이 서스펜디드 디바이스는 두 개 의 저스트레스지수(low stress) 질화 실리콘 $\left(\mathrm{SiN}_{\mathrm{x}}\right)$ 멤브레인 으로 제작되었다. 각각의 질화 실리콘 멤브레인은 6개의 빔으로 서스펜드 된 형태로 구성되어 있다. 각각의 빔 위 엔 백금 $(\mathrm{Pt})$ 전극선이 있으며 이 중 2 개의 전극선은 시료
가 전기적으로 외부와 연결되도록 제작되었다. 전극선과 박 막 시료의 전기적 접촉은 시료를 디바이스 위로 옮긴 후 전자현미경 안에서 전자빔을 이용하여 백금 $(\mathrm{Pt})$ 을 시료와 전극선 위로 증착함으로써 이루어졌다. 4 개의 남은 전극 선은 질화 실리콘 멤브레인에 있는 resistance thermometer (RTD)의 저항을 측정하는데 활용되었다. 측정된 저항을 통 해서 질화 실리콘 멤브레인의 온도를 측정 할 수 있었 다. 한쪽 멤브레인에 있는 RTD에 전류를 흘려 가열하면 멤브레인의 온도가 상승하고, 이때 발생한 열은 박막 시 료를 따라 옆에 있는 다른 멤브레인으로 전달되어 두 번 째 멤브레인의 온도 상승에 기여 하게 된다. 이렇게 두 멤 브레인 간의 온도 차이와 발생하는 제베크전압을 측정하 여, 제베크 계수 및 열전도도를 계산할 수 있었다. 또한 Fig. 4 에서 볼 수 있듯이 가장 안쪽 4 개의 전극선을 이용 한 4-probe 저항을 측정하여 전기전도도 또한 측정할 수 있었다. 자세한 측정 방법은 참고 논문에 열거되어 있다. ${ }^{10)}$

\section{3. 결과 및 고찰}

Fig. 5에서 볼 수 있듯이 박막 시료의 전기전도도는 온 도 상승에 비례해서 증가함을 알 수 있다. 일반적으로 반 도체의 경우 온도 상승에 따라 charge carrier 수가 증가 하기 때문에 전기저항이 감소하는 반면 전기전도도는 상 승하는데, 나노입자가 첨가된 복합 반도체의 경우에도 이 와 같은 현상을 관찰할 수 있었다. 다른 그룹에서 측정 한 같은 박막시료의 상온 전기전도도가 $250 \sim 3001 / \Omega \mathrm{cm}$ 로 알려져 있음을 고려할 때 이번에 측정된 시료의 경우 300 $\mathrm{K}$ 에서 전기전도도가 조금 낮게 측정되었다. $\mathrm{Pt}$ 전극과 시 료의 접촉저항은 온도저하에 따라 상승하는 경향을 보였 으며 $200 \mathrm{~K}$ 이하에서는 전류를 흘려보낼 수 없을 정도 로 contact 저항이 커져 4-probe 저항 측정이 불가능 하 였다.

제베크 계수는 Fig. 6에서 보는 바와 같이 온도상승에 비례해서 증가하였다. 이는 두께가 상이한 박막 시료에 서 동일하게 관찰되었다. $325 \mathrm{~K}$ 에서 측정된 제베크 계수

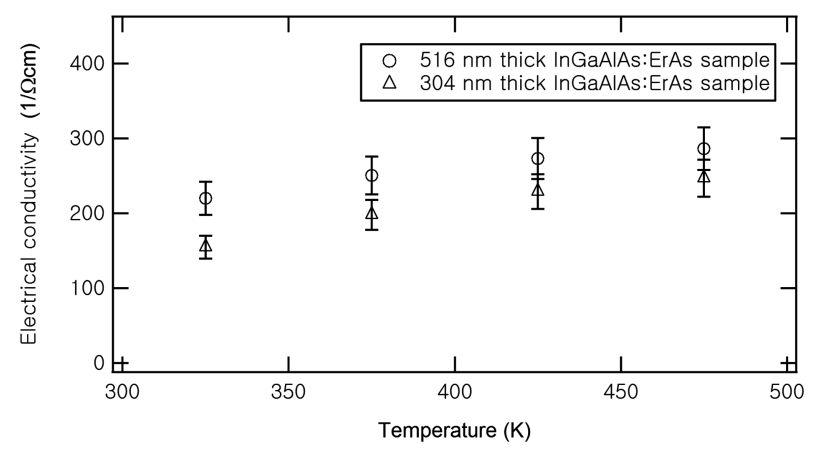

Fig. 5. Measured electrical conductivity as a function of temperature. 


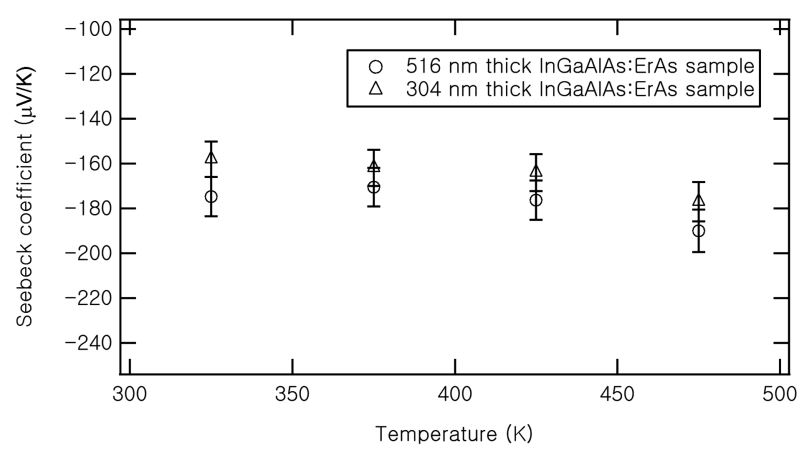

Fig. 6. Measured Seebeck coefficient as a function of temperature.

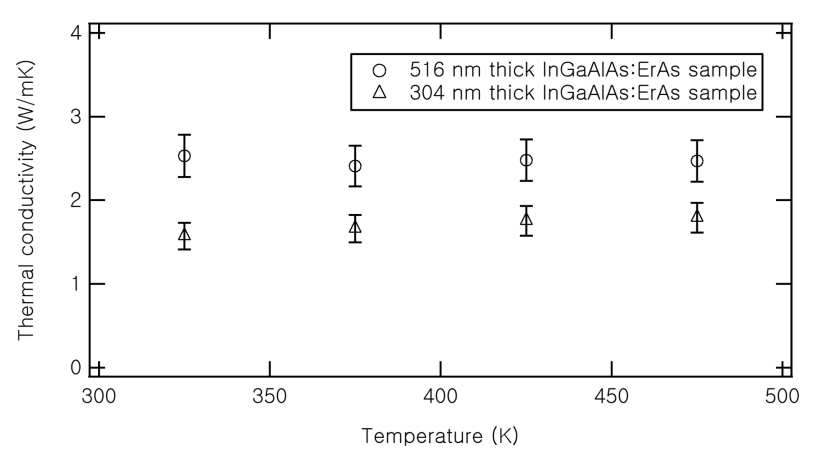

Fig. 7. Measured thermal conductivity as a function of temperature.

는 예상된 비례 증가에 비해서 다소 낮게 측정되었다. 이 는 저온 cryostat의 특성상 상온 근처에서의 온도의 안정 적 유지가 비교적 어렵기 때문에 제베크 계수 측정 시 실험적 오차가 상대적으로 증가할 수 있기 때문으로 생 각된다. 제베크 계수가 음의 값을 보이는 것은 다수의 thermal carrier가 전자임을 말해준다. 이는 InGaAlAs 박 막이 본래 n-type이었기 때문이며, 또한 $\mathrm{Er}$ 도핑을 통해 전자밀도가 높아졌기 때문이다. 제베크 계수의 온도 비례 증가는 온도 상승에 따라 impurity activation이 증가하기 때문이다. 하지만 그 증가정도가 작은 것은 상온에서 이 미 대부분의 impurity activation이 이루어졌기 때문인 것 으로 설명할 수 있다.

Fig. 7는 온도에 따른 열전도도의 특성을 나타내었다. $304 \mathrm{~nm}$ 박막은 $1.6 \sim 1.8 \mathrm{~W} / \mathrm{mK}, 516 \mathrm{~nm}$ 박막은 2.4 2.5 $\mathrm{W} / \mathrm{mK}$ 의 열전도도가 측정되었다. 이러한 측정값은 시료를 제공한 그룹에서 측정한 온도에 따른 열전도도의 변이와 유사하였으며, ${ }^{11)}$ 이는 서스펜디드 디바이스를 이용한 측 정의 신뢰성을 입증하는 것이다. 상이한 두께의 박막 시 료의 측정값이 다른 것은 두께가 얇은 시료일 경우 여 러 식각 공정을 거치면서 박막의 표면에 생기는 여러 defect들이 열전도도에 더 크게 영향을 미치기 때문인 것 으로 이해할 수 있다. 부피 대비 표면적의 비율이 커질 수록 표면 defect로 인한 열전도도가 저하되는 것은 다른 나노선 시료에서도 이미 관측되었다. ${ }^{12)}$ 이는 부피 대비 표

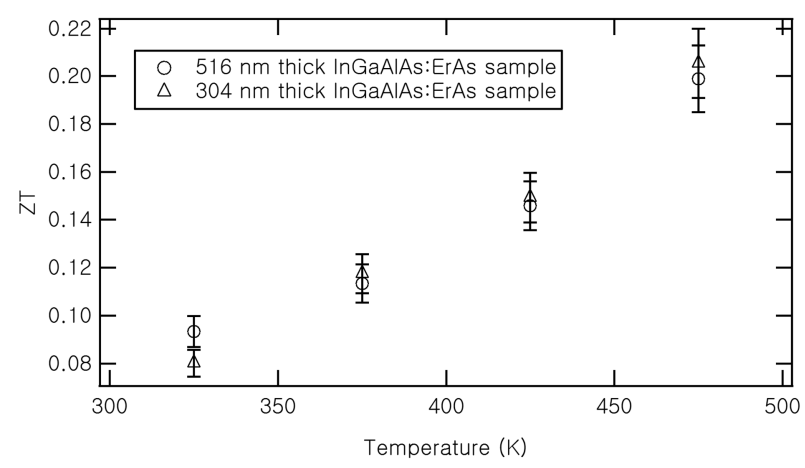

Fig. 8. Measured ZT as a function of temperature.

면적의 비율이 증가할수록 표면 defect에 의한 phonon 산 란 확률이 증가하여 열전달이 방해받게 되므로, 열전도도 가 박막의 두께 감소에 비례해서 감소하는 것으로 이해 할 수 있다.

열전소자의 성능을 나타내는 $Z 7$ 값은 Fig. 8와 같이 측 정되었다. 반도체 또는 반금속 물질과 같이 온도상승에 따라 $Z T$ 값이 증가하는 것을 관찰할 수 있었다. 동일 물 성의 두께가 상이한 시료의 $Z T$ 값을 비교하였을 때 두께 가 얇은 시료에서 $Z T$ 값이 증가함을 알 수 있었다. 예외 적으로 $325 \mathrm{~K}$ 에서는 $516 \mathrm{~nm}$ 시료의 $Z T$ 값이 더 큰 것으 로 나타났으나, 이는 위에서 언급한 바와 같이 $325 \mathrm{~K}$ 에 서 $304 \mathrm{~nm}$ 시료의 제베크 계수가 상대적으로 낮게 측정 되었기 때문으로 생각할 수 있다. 이상의 결과는 물질의 열전성능이 저차원 배열에 따라 벌크와 상이하게 변화할 수 있다는 이론을 실험적으로 증명한 것이며, 기존의 실 험결과와 부합하는 것을 알 수 있다.

열전성능 값을 얻기 위해서는 전기전도도 측정이 반드 시 필요하지만 $\mathrm{Pt}$ 전극과 시료의 접촉저항이 온도 저하에 따 라 증가함에 따라 저온에서의 측정이 불가능한 점, cryostat 의 최대사용온도인 $475 \mathrm{~K}$ 이상 온도에서의 데이터가 부 족한 점은 다음 실험을 통해 보충해야 할 것으로 생각 된다. 또한 $\mathrm{Er}$ 을 첨가하지 않은 시료를 포함한 더 많은 시료를 제작하여 데이터의 신뢰성을 높여야 하는 것은 다 음 과제로 남아있다. 그러나 $325 \mathrm{~K}$ 와 $475 \mathrm{~K}$ 사이의 온 도 영역에서는 저차원 박막 또는 나노선 물질에서 열전 성능이 향상될 수 있음을 실험적으로 확인할 수 있었다.

\section{4. 결 론}

MEMS 방법으로 제작된 서스펜디드 디바이스를 이용하 여 $\mathrm{ErAs}$ 나노입자가 첨가된 $\mathrm{InGaAlAs}$ 박막의 열전특성 을 측정하였다. 평면정렬방향의 (in-plane direction) 전기전 도도, 제베크계수 및 열전도도를 $304 \mathrm{~nm}$ 및 $516 \mathrm{~nm}$ 두께 의 시료에서 측정 및 비교하였다. 열전도도는 전기전도도 와 제베크계수 보다 두께가 얇은 시료에서 더 큰 폭으로 
감소하였으며, 이로 인해 열전성능지수인 ZT값이 증가한 것으로 측정되었다. 이 결과는 비록 동일 물성일지라도 저 차원에서는 벌크물질과 상이한 열전성능을 보일 수 있음 을 실험적으로 증명한 것으로 생각된다.

\section{감사의}

이 논문은 2010학년도 경북대학교 신임교수정착연구비 에 의하여 연구되었으며, 이에 감사드립니다.

\section{참 고 문 헌}

1. L. D. Hicks and M. S. Dresselhaus, Phys. Rev. B, 47, 16631 (1993).

2. N. Mingo, Appl. Phys. Lett., 84, 2652 (2004).

3. T. Koga, X. Sun, S. B. Cronin and M. S. Dresselhaus, Appl. Phys. Lett., 73, 2950 (1998).

4. D. A. Broido and T. L. Reinecke, Phys. Rev. B Condens. Matter, 64, 045324 (2001).

5. G. Chen, M. S. Dresselhaus, G. Dresselhaus, J. P. Fleurial and T. Caillat, Int. Mater. Rev., 48, 45 (2003).
6. L. Shi, D. Li, C. Yu, W. Jang, D. Kim, Z. Yao, P. Kim and A. Majumdar, J. Heat Tran., 125, 881 (2003).

7. J. M. Zide, D. O. Klenov, S. Stemmer, A. C. Gossard, G. Zeng, J. E. Bowers, D. Vashaee and A. Shakouri, Appl. Phys. Lett., 87, 112102 (2005).

8. G. Zeng, J. H. Bahk, J. E. Bowers, J. M. O. Zide, A. C. Gossard, Z. Bian, R. Singh, A. Shakouri, W. Kim, S. L. Singer and A. Majumdar, Appl. Phys. Lett., 91, 263510 (2007).

9. W. Kim, S. L. Singer, A. Majumdar, D. Vashaee, Z. Bian, A. Shakouri, G. Zeng, J. E. Bowers, J. M. O. Zide and A. C. Gossard, Appl. Phys. Lett., 88, 242107 (2006).

10. A. Mavrokefalos, M. T. Pettes, F. Zhou and L. Shi, Rev. Sci. Instrum., 78, 034901 (2007).

11. S. L. Singer, W. Kim, A. Majumdar, J. M. O. Zide and A. C. Gossard, in Proceedings of the sixth International Workshop on Micro and Nanotechnology for Power Generation and Energy Conversion Applications (Berkeley, CA, USA, November 2006) p193.

12. A. I. Hochbaum, R. Chen, R. D. Delgado, W. Liang, E. C. Garnett, M. Najarian, A. Majumdar and P. Yang, Nature, 451, 163 (2008). 